\title{
Increased risk of recurrence of pregnancies complicated by fetal neural tube defects in mothers receiving poor diets, and possible benefit of dietary counselling
}

\author{
K M LAURENCE， NANCI JAMES， MARY MILLER， H CAMPBELL
}

\section{Summary and conclusions}

One hundred and seventy-four women who had previously had a child with a neural-tube defect were assessed retrospectively on the quality of their diets during the first trimester of that pregnancy, between pregnancies, and during the first trimester of other pregnancies. They were then studied prospectively during the first trimester of 186 following pregnancies and the outcome of these was recorded. One hundred and three women (with 109 pregnancies) were given dietary counselling before the pregnancy, the remaining 71 (with 77 pregnancies) not being counselled. Seventyeight $(72 \%)$ of the counselled women improved their diet compared with only nine $(12 \%)$ of the uncounselled women. The difference was significant $(p<0.001)$. There were three recurrences of neural-tube defects in the counselled women $(3 \%)$ and five recurrences in the uncounselled $(7 \%)$. Although this difference was not significant, the relative risk in the counselled group was reduced to less than half of that in the uncounselled group. All eight recurrences occurred in the 45 pregnancies in women taking poor diets $(18 \%)$, whereas there were no recurrences in the 141 other pregnancies. This difference is significant $(p<0 \cdot 001)$.

It is concluded that women receiving adequate diets have a lower incidence and recurrence of fetal neuraltube defects than women receiving poor diets and that dietary counselling may be effective in reducing the incidence of fetal neural-tube defects.

\section{Introduction}

The incidence of fetal neural-tube defects in all surveys carried out in the British Isles has consistently been greater in mothers in social classes 4 and 5 than in those in social classes 1 and $2,{ }^{1-5}$ though more recently this difference has been less pronounced, possibly reflecting the general improvement in the standard of living. ${ }^{3}$ A relation undoubtedly exists between social class and maternal diet, with several studies showing that mothers in social classes 4 and 5 more often have a poor diet in early pregnancy and sometimes suffer from deficiencies of essential dietary constituents. ${ }^{6}$ With this in mind we undertook a study of the diet of women who had had pregnancies complicated by fetal neural-tube defects as part of a larger survey of the possible biochemical abnormalities during early pregnancy of women who were at increased risk of such pregnancies. We report here some of the findings of the dietary part of the study together with the effect of dietary counselling.

Department of Child Health, Welsh National School of Medicine, Cardiff CF4 4XN

$K M$ LAURENCE, DSC, FRCP, professor of paediatric research

NANCI JAMES, MB, MRCP, fieldworker

MARY MILLER, BM, DCH, fieldworker

Department of Medical Statistics, Welsh National School of Medicine H CAMPBELL, FRCP, FFCM, professor

\section{Patients and methods}

Women resident in Glamorgan and Gwent who had had a pregnancy complicated by fetal neural-tube defects (anencephaly, encephalocele, and spina bifida) between 1954 and 1969 were traced through malformation registers, maternal and paediatric records, local authority records, and other sources. Those under 35 years of age at the time of the study were visited in their homes by medically qualified fieldworkers, NJ visiting 479 mothers in West Glamorgan and the western part of Mid Glamorgan (area $A$ ) and MM visiting 426 in the eastern part of Mid Glamorgan, South Glamorgan, and the western portion of Gwent (area B). These two areas were studied by Richards ${ }^{7}$ during 1964-6 and had similar incidences of neural-tube defects-namely, 7.8/1000 singleton births in area $A$ and 6.6/1000 in area B. Laurence et $a l,^{3}$ however, did not include a large part of area $\mathrm{A}$ in their studies at that time.

During home visits a questionnaire was completed giving details of the woman's diet when she was not pregnant (interpregnancy period), during the first trimester of the pregnancy complicated by a neural-tube defect that placed the woman on our register (index pregnancy), and during the first trimester of any other pregnancy (other pregnancies).

A simple diet sheet was used that provided a general pattern for meals and a check list showing the amounts of food consumed during the average week and listing first-class proteins, dairy products, milk, fresh vegetables, fruits and salads, whole-grain cereals, refined cereals, refined carbohydrates, potato and potato products, and fats. The diets were adjudged by one of us (NJ) into three broad groups. Good diets were those with a good intake of all essential food including first-class protein and no imbalance such as excessive amounts of potato and potato products, refined cereals and carbohydrates, sweets, chocolates, and soft drinks; moderate diets were those containing less than the recommended amount of essential items of $\operatorname{diet}^{8}$ (generally a limited quantity of first-class protein and small quantities of fresh fruit and vegetables) with or without imbalance; and poor diets were those with a deficient intake of first-class protein, usually no fruit or vegetables, and generally a severe imbalance with excessive amounts of carbohydrates. Any illness, anorexia, or vomiting that had occurred during the first trimester was noted.

Those women in area $\mathrm{A}$ who were planning to have further children and were willing to co-operate were counselled to improve their diets and to stop smoking not later than the time when contraceptive precautions were stopped. Those in area B were not counselled. Both groups of women were instructed to report to us within six weeks of a missed menstrual period. The mother was revisited as soon as possible after notification had been received, and inquiries were made about the quality of the diet during the pregnancy and about any anorexia or vomiting, drugs, or illness. This pregnancy was termed the project pregnancy.

\section{Results}

Altogether 905 women had had pregnancies complicated by neural-tube defects and were visited. One hundred and ninety-two of these women notified us of a further pregnancy between 1969 and 1975. Eighteen pregnancies were excluded because the notification reached us more than six weeks after the missed menstrual period. This left 186 project pregnancies in 174 women, 12 having two pregnancies. In area A (counselled) 103 women had 109 project pregnancies, while in area $B$ (uncounselled) 71 women had 77 project pregnancies (table I).

Table I shows that there were no statistical differences between areas $A$ and $B$ in the qualities of the diets reported during the interpregnancy period and during previous pregnancies. In both areas the quality of the diet was worse during the index pregnancy than 
during the interpregnancy period and during other pregnancies $(p<0.001)$. There was no difference in area $B$ between the diet during the project pregnancy and that during the other pregnancies, whereas in area A the proportion of women taking a good diet was considerably higher during the project pregnancy compared with the other pregnancies.

Table II shows the change in diet during the project pregnancy compared with the previous pregnancies and the interpregnancy period. In area $B$ there was essentially no change; a few women improved their diets but an equal number took a poorer diet. In area $\mathrm{A}$, however, the women responded to the counselling: compared with the interpregnancy period 58 had improved their diet and only seven taken a poorer diet $(p<0.01)$. Most of the women whose diet had deteriorated had suffered excessive nausea or vomiting in early pregnancy.

Table III shows that among the counselled women three of the 109 project pregnancies $(3 \%)$ resulted in the birth of an infant with a neural-tube defect compared with five of the $77\left(7^{\circ}\right)$ among the uncounselled women. Although this difference might well have

TABLE I-Quality of diet before and during project pregnancy

\begin{tabular}{|c|c|c|c|c|c|c|c|}
\hline \multirow{2}{*}{ Period of diet } & \multirow{2}{*}{$\begin{array}{c}\text { Counselling } \\
\text { state }\end{array}$} & \multicolumn{4}{|c|}{ Quality of diet } & \multicolumn{2}{|c|}{ Significance* } \\
\hline & & Good & Fair & Poor & Total & $x^{2}$ & Probability \\
\hline $\begin{array}{l}\text { Interpregnancy } \\
\text { period }\end{array}$ & $\left\{\begin{array}{l}\text { Counselled } \\
\text { Not counselled }\end{array}\right.$ & $\begin{array}{l}14 \\
10\end{array}$ & $\begin{array}{l}63 \\
44\end{array}$ & $\begin{array}{l}26 \\
17\end{array}$ & $\begin{array}{r}103 \\
71\end{array}$ & $0 \cdot 41$ & NS \\
\hline Index pregnancy & $\begin{array}{l}\text { Counselled } \\
\text { Not counselled }\end{array}$ & $\begin{array}{l}9 \\
8\end{array}$ & $\begin{array}{l}36 \\
29\end{array}$ & $\begin{array}{l}58 \\
34\end{array}$ & $\begin{array}{r}103 \\
71\end{array}$ & $2 \cdot 28$ & NS \\
\hline Other pregnancies & Counselled & 13 & 33 & 21 & $\begin{array}{l}67 \\
56\end{array}$ & 0.23 & NS \\
\hline Project pregnancy & $\begin{array}{l}\text { Not counselled } \\
\text { Counselled } \\
\text { Not counselled }\end{array}$ & $\begin{array}{l}10 \\
40 \\
13\end{array}$ & $\begin{array}{l}30 \\
49\end{array}$ & $\begin{array}{l}10 \\
20 \\
25\end{array}$ & $\begin{array}{l}109 \\
77\end{array}$ & $10 \cdot 37$ & $\mathrm{p}<0.001$ \\
\hline & lled & 13 & 39 & 25 & & & \\
\hline
\end{tabular}

*Significance of difference between those counselled and not counselled.

\section{Discussion}

In any prospective study it is difficult to obtain a sample size large enough to show important clinical differences when the incidence of the disease is low. In the present study the incidence of pregnancies complicated by neural-tube defects in women with a history of such pregnancies might be expected to be about $5 \%$. A case-control prospective study that would detect a $50 \%$ improvement in the recurrence rate with a power of 0.80 and a significance of $p<0.05$ would require a study of about 1800 pregnancies, which in turn would require a preliminary study of possibly five times this number of mothers who had had a pregnancy complicated by a neural-tube defect to obtain enough mothers who wished to have a further pregnancy. Our study cannot be expected to show a significant difference, but the reduction in the relative risk was more than $50 \%$, though based on small numbers. This might easily have been the result of chance had there been no effect of dietary change on recurrence (null hypothesis); but if the alternative hypothesis were true the result would be fundamentally important in understanding the aetiology of the malformation and the possibility of intervening to prevent it.

The logistics make it impossible to mount a statistically valid study, yet this means that a potentially effective treatment might have to be withheld from mothers at serious risk of further pregnancies complicated by neural-tube defects. We therefore consider that we should publish our results and stop the trial in the hope that other centres might take up the challenge and that collateral arguments may be persuasive.

The accumulated epidemiological data from family studies

TABLE II-Change in quality of diet during project pregnancy compared with previous periods

\begin{tabular}{|c|c|c|c|c|c|c|c|}
\hline \multirow{2}{*}{$\begin{array}{l}\text { Project pregnancy } \\
\text { compared with: }\end{array}$} & \multirow{2}{*}{ Counselling state } & \multicolumn{4}{|c|}{ Change in quality of diet } & \multicolumn{2}{|c|}{ Significance* } \\
\hline & & Improvement & No change & Deterioration & Total & $x^{2}$ & Probability \\
\hline Interpregnancy period & $\left\{\begin{array}{l}\text { Counselled } \\
\text { Not counselled }\end{array}\right.$ & $\begin{array}{l}58 \\
16\end{array}$ & $\begin{array}{l}44 \\
43\end{array}$ & $\begin{array}{r}7 \\
18\end{array}$ & $\begin{array}{r}109 \\
77\end{array}$ & $21 \cdot 25$ & $\mathrm{p}<0.001$ \\
\hline Index pregnancy & $\left\{\begin{array}{l}\text { Counselled } \\
\text { Not counselled }\end{array}\right.$ & $\begin{array}{r}78 \\
9\end{array}$ & $\begin{array}{l}29 \\
63\end{array}$ & $\begin{array}{l}2 \\
5\end{array}$ & $\begin{array}{r}109 \\
77\end{array}$ & $64 \cdot 8$ & $\mathrm{p}<0.001$ \\
\hline Other pregnancies & $\left\{\begin{array}{l}\text { Counselled } \\
\text { Not counselled }\end{array}\right.$ & $\begin{array}{r}44 \\
3\end{array}$ & $\begin{array}{l}19 \\
48\end{array}$ & $\begin{array}{l}4 \\
5\end{array}$ & $\begin{array}{l}67 \\
56\end{array}$ & $49 \cdot 2$ & $\mathrm{p}<0.001$ \\
\hline
\end{tabular}

*Significance of difference between those counselled and not counselled.

TABLE III-Outcome of project pregnancy by diet during the pregnancy

\begin{tabular}{|c|c|c|c|c|c|c|}
\hline \multirow{2}{*}{ Outcome of pregnancy } & \multirow{2}{*}{$\begin{array}{c}\text { Counselling } \\
\text { state }\end{array}$} & \multicolumn{4}{|c|}{ Quality of diet } & \multirow{2}{*}{ Significance } \\
\hline & & $\overline{\text { Good }}$ & Fair & Poor & All diets & \\
\hline Normal & $\left\{\begin{array}{l}\text { Counselled } \\
\text { Not counselled }\end{array}\right.$ & $\begin{array}{l}40 \\
13\end{array}$ & $\begin{array}{l}46 \\
39\end{array}$ & $\begin{array}{l}10 \\
12\end{array}$ & $\begin{array}{l}96 \\
64\end{array}$ & $p<0.02$ \\
\hline Miscarriage & $\left\{\begin{array}{l}\text { Counselled } \\
\text { Not counselled }\end{array}\right.$ & & 3 & $\begin{array}{l}7 \\
8\end{array}$ & $\begin{array}{r}10 \\
8\end{array}$ & NS \\
\hline Neural-tube defects & $\left\{\begin{array}{l}\text { Counselled } \\
\text { Not counselled }\end{array}\right.$ & & & $\begin{array}{l}3 \\
5\end{array}$ & $\begin{array}{l}3 \\
5\end{array}$ & NS \\
\hline $\begin{array}{l}\text { Normal or miscarriage } \\
\text { Neural-tube defects }\end{array}$ & $\begin{array}{l}\text { All women } \\
\text { All women }\end{array}$ & 53 & 88 & $\begin{array}{r}3 \\
87 \\
8\end{array}$ & $\begin{array}{r}178 \\
8\end{array}$ & $\{p<0.001$ \\
\hline Total & & 53 & 88 & 45 & 186 & \\
\hline
\end{tabular}

arisen by chance $\left(\chi^{2}=0.75, p>0.05\right)$, the relative risk to the counselled group had been reduced to 0.4 of the risk to the uncounselled group. All eight cases had occurred in the 45 women whose diet during the project pregnancy was considered to be poor, and this difference when compared with the absence of cases in the 141 women taking good or fair diets was significant by Fisher's exact test $(p<0.001)$. Of the three cases in women who had received counselling, two had a poor diet owing to hyperemesis gravidarum and one had failed to follow the dietary advice.

Eighteen miscarriages occurred, 10 among the counselled women $(9 \%)$ and eight among the uncounselled women $(10 \%)$; this difference is not significant. The products of conception were examined pathologically in four cases. Fifteen of these miscarriages, however, occurred in the 45 women taking a poor diet $(33 \%)$, whereas only three $(2 \%)$ occurred in the 141 who were receiving a fair or good $\operatorname{diet}\left(\chi^{2}=33.6, \mathrm{p}<0.001\right)$. suggest that the neural-tube defects almost certainly belong to the large group of multifactorial abnormalities. In these abnormalities the malformation is started during the first stage of development by environmental factors acting on the fetus when it is susceptible through inherited characteristics carried on several genes. ${ }^{910}$ From experimental evidence it is probable that a number of factors will be found to be responsible. Some of these factors act as trigger mechanisms when a certain threshold level is reached; others may act only when deficient. Only one drug, aminopterin, a powerful folic acid antagonist, now rarely used, has been proved to produce neural-tube defects in man. ${ }^{11}$ This suggests that folic acid may act as a deficiency factor when the available concentration falls below a certain threshold. No other single deficiency, dietary constituent, agent, drug, or infection has been proved to be a major cause, although several have been implicated. Smoking has been suggested as a possible factor, ${ }^{12-14}$ and in this study $21(20 \%)$ of the 103 counselled mothers were non-smokers during the project pregnancy compared with $10(14 \%)$ of the 71 uncounselled mothers. This difference was not significant.

The results of this study suggest that improving the quality of the diet, especially during the first trimester of pregnancy in women at risk of pregnancies complicated by fetal neural-tube defects, may improve some environmental factors acting on the fetus. All the recurrences and nearly all the miscarriages occurred following pregnancies in women receiving a poor or severely unbalanced diet. In a few cases there may have been additional factors that have been suggested as possible aetio- 
logical triggers, such as a hormonal pregnancy test ${ }^{15}$ or a viral infection..$^{16}$ The study by Smithels $e t$ al, ${ }^{17}$ although it was not a controlled trial and used multivitamin supplementation, would seem to indicate the possible success of dietary improvement.

We conclude, therefore, that dietary counselling was effective in south Wales. All eight recurrences were in mothers whose diet was poor during the early stages of the project pregnancy. Counselling may have reduced the incidence of recurrence by $60 \%$, but even more effective counselling may be possible.

Advice on diet should be part of a health education programme that should start in school. Women should be taught what is an adequate and balanced diet and how important such a diet is, especially before and during pregnancy. As the dietary habits of a woman are determined largely by what she learns in the parental home, ${ }^{18}$ however, to be effective any dietary advice would have to be reinforced by the press and the media. In the case of women at increased risk of pregnancy complicated by neural-tube defects because of a history of such pregnancies or because a close relation has a neural-tube defect, special dietary counselling may be required well before any pregnancy is begun.

We thank the women who took part in this study. This study was supported by Action Research for the Crippled Child, the Manpower Services Commission, and Tenovus.

Requests for reprints should be addressed to Professor $\mathrm{K} M$ Laurence, Department of Child Health, Welsh National School of Medicine, Heath Park, Cardiff CF4 4XN.

\section{References}

${ }^{1}$ Record, RG, McKeown T. Congenital malformations of the central nervous system 1-survey of 930 cases. Br 7 Prev Soc Med 1949;3: 183-219.

${ }^{2}$ Williamson EM. Incidence and family aggregation of major congenital malformations of the central nervous system (a survey of 100 families in Southampton). 7 Med Genet $1965 ; 2: 161-72$.

3 Laurence KM, Carter CO, David PA. Major central nervous system malformations in South Wales. II. Pregnancy factors, seasonal variation, and social class effects. $\operatorname{Br} \mathcal{F}$ Prev Soc Med 1968;22:212-22.

${ }^{4}$ Carter CO, Evans K. Spina bifida and anencephalus in Greater London. 7 Med Genet 1973;10:209-34.

${ }^{5}$ Elwood JM, Elwood JH. Epidemiology of anencephalus and spina bifida. Oxford: Oxford University Press, 1980.

${ }^{6}$ Smithells RW, Sheppard S, Schorah CJ. Vitamin deficiencies and neural tube defects. Arch Dis Child 1976;51:944-50.

7 Richards IDG. Congenital defects in South Wales. PhD thesis. University of Wales. 1971

${ }^{8}$ Department of Health and Social Security. Recommended intake of nutrients for the United Kingdom. Reports on Public Health and Medical Subjects; Great Britain. 1969; No 120.

${ }^{9}$ Carter CO, David PA, Laurence KM. A family study of central nervous system malformations in South Wales. $\mathcal{f}$ Med Genet 1968;5:81-106.

${ }^{10}$ Carter CO. Clues to the aetiology of neural tube malformations. Dev Med Child Neurol 1974;16,suppl 32:3-15.

11 Thiersch JB. Therapeutic abortions with folic acid antagonist 4-amniopteroylglutamic acid (4 amino PGA) administered by the oral route. Am F Obstet Gynecol $1952 ; 63: 1298-304$.

${ }^{12}$ Andrews J, McGarry JM. A community study of smoking in pregnancy. fournal of Obstetrics and Gynaecology of the British Commonwealth 1972; 79:1057-73.

13 Choi NW, Klaponski J. Neural tube defects: an epidemiological elicitation of etiological factors. Neurology (Minneap) 1970;20:399-400.

${ }^{14}$ Kelsey JL, Dwyer T, Holford TR, Bracken MB. Maternal smoking and congenital malformations. F Epidemiol Community Health 1978;32: 102-7.

15 Gal I, Kiman B, Sterm J. Hormonal pregnancy tests and congenital malformation. Nature 1967;216:83.

${ }^{16}$ Saxén K, Hjelt L, Sjöstedt JE, Hakossalo J, Hakosalo H. Asian influenza during pregnancy and congenital malformations. Acta Pathol Microbiol Scand 1960;49:114-26.

17 Smithels RW, Sheppard S, Schorah CJ, et al. Possible prevention of neural tube defects by periconceptional vitamin supplementation. Lancet $1980 ; \mathrm{i}: 339-40$.

18 Emanuel I, Sever LE. Questions concerning the possible association of potatoes and neural tube defects and an alternative hypothesis relating to maternal growth and development. Teratology $1974 ; 8: 317-2 n$

(Accepted 20 October 1980)

\title{
Adjuvant chemotherapy for breast cancer: side effects and quality of life
}

\author{
B V PALMER, G A WALSH, J A MCKINNA, W P GREENING
}

\section{Summary and conclusions}

In a trial of postoperative adjuvant chemotherapy women with primary breast cancer and spread to one or more axillary nodes were randomised to receive a six-month course of either the single agent chlorambucil or the five-drug combination of chlorambucil, methotrexate, fluorouracil, vincristine, and adriamycin. On completing the treatment 47 patients were asked to fill in questionnaires at home on the side effects of treatment and its influence on the quality of their life. Side effects including nausea, vomiting, malaise, and alopecia had been severe enough to interfere with their lifestyle in $9(42 \%)$ of the patients who had received the single agent and $19(79 \%)$ of those who had received

Breast Unit, Royal Marsden Hospital, London SW3 6JJ

B V PALMER, FRCS, senior surgical registrar (present address: Royal Sussex County Hospital, Brighton)

G A WALSH, secretary of unit

J A MCKINNA, FRCS, consultant surgeon

W P GREENING, FRCS, consultant surgeon multiple-drug treatment. Various other side effects were reported by a few patients. Seven (29\%) of the patients who had received the multiple-drug schedule voluntarily added that the treatment had been "unbearable" or "could never be gone through again."

The proportion of patients who had experienced severe side effects while receiving the treatment was considerable; hence such adjuvant chemotherapy is justifiable only if it will substantially improve a patient's prognosis.

\section{Introduction}

Results of using adjuvant chemotherapy after mastectomy for patients with primary breast cancer encouraged the hope that chemotherapy might be a major advance in the treatment of these patients. ${ }^{1-4}$ Various trials were set up to establish the most effective regimens and assess which patients might be helped. Thus Bonadonna et $a l^{5}$ and Fisher et $a l^{6}$ showed little benefit in postmenopausal patients. Results of most studies indicated that the toxicity of the various drug regimens was not troublesome. 